\title{
Cabaran guru prasekolah dalam menerapkan Pendidikan Stem
}

\author{
Khusnidar Muhammad Daud \\ Sekolah Menengah Atas Fajar Hidayah Aceh \\ Indonesia \\ email: khusnidar@gmail.com
}

DOI: https://doi.org/10.37134/jpsmm.vol9.2.4.2019

Published: 20 December 2019

\begin{abstract}
Abstrak
Guru berperanan penting dalam menyokong kanak-kanak bagi menjayakan pendidikan STEM. Kajian kes ini bertujuan untuk menerangkan mengenai cabaran yang dihadapi oleh guru prasekolah dalam menerapkan pendidikan STEM ke atas kanak-kanak umur 4 sehingga 6 tahun. Peserta kajian ini terdiri daripada 2 orang guru dan 36 orang kanak-kanak. Data diperolehi daripada pemerhatian selama tiga hingga 4 bulan dan temu bual guru. Dapatan kajian menunjukkan cabaran utama penerapan pendidikan STEM adalah guru kurang menguasai pedagogi dalam konteks pengajaran sains dan kekurangan alat untuk menjalankan aktiviti penyiasatan. Selain itu, tumpuan kanak-kanak semasa proses pembelajaran berlangsung serta persepsi ibu bapa turut menjadi cabaran dalam menerapkan pendidikan STEM di prasekolah. Dengan mengenalpasti cabaran ini, langkah mengatasinya dapat diambil bagi memastikan pendidikan STEM di prasekolah dapat diterapkan.
\end{abstract}

Kata kunci: Cabaran, Guru Prasekolah, Penerapan, Pendidikan STEM

\begin{abstract}
Teachers play an important role in supporting children to achieve STEM education. This case study aims to explore the challenges faced by preschool teachers in applying STEM education to children ages 4 to 6. The participants consisted of 2 teachers and 36 children. Data were obtained from three to 4 month observations and teacher interviews. The findings show that the challenges of STEM education applications is that teacher lack of pedagogy in science and tools to conduct the investigation activities. In addition, children's focus during the learning process as well as parents' perceptions also pose a challenge in implementing STEM education in preschool. By identifying these challenges, steps can be taken to ensure that STEM education in preschool is implemented.
\end{abstract}

Keywords: Challenges, Preschool Teachers, Implementation, STEM Education

\section{PENGENALAN}

Persaingan dan pekerjaan masa hadapan sangat berlainan dengan masa kini. Ianya lebih menekankan kepada kemahiran-kemahiran abad-21, seperti bekerjasama, menyelesaikan masalah, berfikir kritis dan inovatif, berkomunikasi, memiliki kreativiti yang tinggi dan kemahiran analitik. Pendidikan STEM telah dianggap sebagai sesuatu yang perlu diajarkan dan dikuasai oleh pelajar terutama dimulai pada peringkat awal bagi mempersiapkan generasi dalam menghadapi persaingan abad ke-21 (McClure et al. 2017). Pendidikan STEM menjadi perbincangan dalam semua kalangan terutama bagi pendidikan awal kanak-kanak dalam menerapkan pendidikan STEM. Mereka menjadi lebih termotivasi dalam menekuni bidang pendidikan STEM apabila ianya diperkenalkan pada peringkat awal kanak-kanak (Sobey, 2019). Sehingga sangat diperlukannya guru yang menguasai dan memiliki kualifikasi yang tinggi dalam mengajarkan pendidikan STEM agar tujuan yang diharapkan dapat tercapai dengan baik. Namun, dalam usaha untuk mewujudkan harapan ini, masih banyak cabaran yang berlaku terutama dari aspek guru. Belum semua guru didedahkan mengenai penerapan STEM sehingga mereka kurang memiliki pengetahuan mengenai pelaksanaan STEM yang sesuai, apatah lagi pendidikan STEM merupakan sesuatu yang baharu. 


\section{PERNYATAAN MASALAH}

Sehubungan dengan wujudnya aspirasi negara Malaysia untuk mencapai kejayaan dalam bidang industri pada tahun 2020, maka perhatian dalam pengajaran dan pembelajaran sains semakin meningkat pula. Masyarakat yang diharapakan adalah mereka yang memiliki azam yang tinggi dalam memajukan pembangunan negara dengan pelbagai kebolehan yang dimilikinya, seperti mampu berinovasi dan memiliki kreativiti untuk menghasilkan sesuatu produk dalam pelbagai bidang. Bagi mewujudkan harapan tersebut maka pendidikan STEM merupakan satu pendekatan yang dapat melatih pelajar dalam mewujudkan aspirasi Negara di tahun 2020. Peningkatan kualiti dalam STEM yang memiliki kelayakan sangat diperlukan dalam meningkatkan kesejahteraan kehidupan sosial, produktiviti ekonomi dan keselamatan $(\mathrm{Li}, 2014)$. Sehingga perlu adanya penerapan pendidikan STEM yang dimulai daripada peringkat awal terutama prasekolah. Aminah Ayob et al. (2015) berpendapat bahawa pendidikan STEM perlu dimulakan daripada peringkat awal kanak-kanak kerana pada peringkat ini kanak-kanak lebih sering menanyakan persoalan mengenai segala sesuatu kepada orang dewasa yang berada di persekitaran mereka terutama ibu bapa dan guru. Oleh itu, guru harus terlebih dahulu memiliki pengetahuan dan kebolehan dalam menjalankan bidang pendidikan STEM yang merupakan penyepaduan daripada pelbagai bidang pengetahuan iaitu sains, teknologi, kejuruteraan dan matematik.

Kajian yang dijalankan oleh Aini Aziziah Ramli et al. (2017) mendapati bahawa guru masih kurang bersedia dalam menerapkan pendidikan STEM. Kajian yang dijalankan ke atas sepuluh orang guru ini mendapati bahawa hanya seramai tiga orang guru sahaja yang memiliki kemampuan dan kesiapan dalam menjalankan pendidikan STEM di kelasnya. Selebihnya tujuh orang diantara sepuluh orang guru yang dikaji didapati bahawa belum memiliki kesiapan dalam menerapkan pendidikan STEM dengan pelbagai alasan, diantaranya ialah guru kurang kepakaran dan keyakinan dalam hal ini. Selain itu, mereka juga menyatakan bahawa fasiliti yang tersedia di dalam makmal belum menyokong untuk menjalankan aktiviti pembelajaran STEM dan kekurangan bahan pengajaran juga menjadi satu cabaran bagi guru. Bers (2008) juga berpendapat bahawa cabaran pertama yang dihadapi oleh guru dalam menjalankan STEM terutama untuk kalangan kanak-kanak diantaranya ialah kurangnya pengetahuan dan pemahaman guru dalam bidang kejuruteraan dan teknologi serta cabaran pada aspek pedagogi guru untuk menyesuaikan perkembangan kanak-kanak semasa menerapkan STEM di dalam bilik darjah.

\section{PENGENALAN STEM}

National Science Foundation (NSF) telah menggunakan istilah STEM dengan merujuk kepada kurikulum empat bidang pelajaran utama iaitu sains, teknologi, kejuruteraan dan matematik. Akronim ini terus digunakan bagi menjelaskan ke semua mata pelajaran STEM iaitu sains, teknologi, kejuruteraan dan matematik (Sanders, 2009). Diantaranya ialah STEM merupakan suatu usaha dalam menggabungjalinkan empat mata pelajaran ke dalam sebuah pelajaran, unit ataupun kelas (Moore et al. 2016). Selain itu, Kelley dan Knowles (2016) juga beranggapan bahawa STEM adalah suatu pendekatan yang mengajarkan dua atau lebih bidang pelajaran STEM yang bersepadu bagi meningkatkan pembelajaran pelajar. Sementara itu Stohlmann et al. (2012) dalam menjalankan pendidikan STEM yang bersepadu memerlukan suatu usaha dan juga masa bagi merancang pembelajaran yang berkesan. Brown et al. (2011) juga telah berpendapat bahawa pengajaran disiplin ilmu sains, teknologi, kejuruteraan dan matematik oleh guru di sekolah dengan tidak memisahkan kesemua bidang namun adanya persepaduan antara ke empat bidang ilmu tersebut.

\section{PENDIDIKAN STEM}

Kementerian Pendidikan Malaysia (2015) menyebutkan bahawa pendidikan STEM bermaksud untuk menggabungkan semua bidang pengetahuan STEM dalam proses pengajaran dan pembelajaran yang 
dimulai daripada peringkat sekolah untuk memupuk minat generasi masa sekarang dalam menekuni bidang pendidikan STEM. Winarni et al. (2016) dalam kajiannya membahas bahawa dalam pendidikan STEM memberikan peluang kepada pelajar untuk mengembangkan kreativiti mereka semasa berusaha dalam menyelesaikan suatu permasalahan. Apabila pendidikan STEM dijalankan dengan baik, maka dapat membantu pelajar untuk menguasai kemahiran-kemahiran abad ke-21, seperti bekerjasama, menyelesaikan masalah, berkomunikasi, kreatif dan mampu dalam menggunakan pelbagai media atau peralatan teknologi bagi memudahkan pekerjaan dalam menjalani kehidupan seharian. Torres-Crespo, Kraatz dan Pallansch (2014) berpendapat bahawa pemikiran STEM dapat menjadikan pelajar lebih mampu dalam berfikir secara kritis dan logis yang akhirnya menjadikan mereka seseorang yang aktif dan dapat memberikan manfaat bagi masyarakat dalam menyelesaikan pelbagai masalah kehidupan.

Masyarakat global pada zaman ini memiliki pelbagai minat dalam bidang teknologi. Namun, masih terdapat juga ramai guru prasekolah yang kurang memberikan tumpuannya kepada teknologi ataupun kejuruteraan untuk peringkat awal kanak-kanak. Mereka lebih tertarik hanya dengan bidang sains serta matematik. Menurut pendapat Cunha dan Heckman (2007), pendidikan yang dijalankan pada peringkat awal kanak-kanak menjadikan mereka dapat mengingat pengetahuan yang diperolehi lebih lama berbanding dengan pengajaran pada peringkat seterusnya dan pengajaran juga dapat lebih menjimatkan kos yang diperlukan. Bers (2008) menyatakan terdapat dua cabaran yang paling utama bagi guru dalam menjalankan pendidikan STEM ke dalam bilik darjah pada peringkat kanak-kanak. Pertama, guru kurang kefahaman dan juga pengetahuan mengenai teknologi dan kejuruteraan. Guru juga menghadapi cabaran dalam segi pendekatan pedagogi yang lebih sesuai dijalankan untuk perkembangan kanak-kanak. Sedangkan cabaran kedua adalah diperlukan persediaan teknologi baharu yang sesuai dengan perkembangan serta keupayaan generasi zaman sekarang; Apabila hal ini tidak dapat terpenuhi, maka sudah pasti guru menghadapi kesukaran dalam penggunaan teknologi yang dapat diterapkan di dalam pembelajaran. Kajian daripada McConnel (2017) terhadap 6588 orang guru sains dan matematik pada peringkat sekolah menengah mendapati bahawa impak sosioekonomi, autonomi guru (Jones et al. 2003), sokongan pentadbir, dan juga kepuasan guru terhadap gaji yang diterimanya (Hanushek \& Rivkin, 2007) sangat mempengaruhi keikhlasan guru dalam menerapkan pendidikan STEM. Selain itu, pengalaman lamanya guru mengajar juga menjadi satu isu dalam pelaksanaan penddikan STEM (Hanushek et al. 2004).

\section{OBJEKTIF}

Objektif kajian ini ialah untuk meneroka cabaran yang dihadapi oleh guru dalam menerapkan pendidikan STEM dalam kalangan kanak-kanak prasekolah.

\section{METODOLOGI}

Kajian ini merupakan kajian kualitatif pelbagai kes (multiple case design) yang telah dipelopori oleh Yin (2015). Kajian ini bertujuan untuk memberikan suatu kefahaman terhadap sesuatu fenomena dengan terperici. Kajian kualitatif dapat mencungkil permasalahan yang rumit dan kompleks dengan mendalama (Denzin \& Lincoln, 2000). Kajian kes merupakan suatu strategi yang mengkaji sesuatu fenomena yang berlaku di lingkungan sebenar secara menyeluruh (Tight, 2017). Kajian yang dijalankan ini fokus untuk memahami dan meneroka secara mendalam terhadap aktiviti yang berkaitan dengan cabaran guru dalam menjalankan pendidikan STEM. Kajian ini tidaklah bertujuan untuk membuat ramalan ataupun generalisasi terhadap suatu fenomena (Merriam, 1998), namun bertujuan untuk mendapatkan kefahaman terhadap cabaran yang dihadapi oleh guru. Setiap metodologi yang dijalanakan dalam kajian mestilah memilii kekuatan dan kelemahan. Oleh itu, yang menjadi kekuatan dalam menjalankan kajian kes ini adalah dapat memberikan manfaat yang luas semasa merangkumi deskripsi dan konsep apabila sesebuah kes dikaji (Creswell et al. 2007). Adapun kelemahan dalam menjalankan kajian kes iaitu hasil daripada kajian sukar untuk digeneralisasikan 
kepada individu atau kumpulan lainnya, sebab setiap kes adalah unik dan tidak boleh diwakilkan kepada kes-kes lainnya (Othman Lebar, 2017).

Kajian ini melibatkan kajian lapangan untuk melihat keadaan yang sebenar sehingga pengkaji sendiri telah berada di Tadika Pusat Penyelidikan Perkembangan Kanak-kanak Negara Universiti Pendidikan Sultan Idris yang telah menjadi lokasi kajian. Kajian kes ini dijalankan ke atas 36 orang kanak-kanak prasekolah (20 orang berusia 4+ dan 16 orang berusia 5+) beserta 2 orang guru. Setiap kumpulan kanak-kanak masing-masing menghasilkan dua projek sehingga jumlah keseluruhan projek adalah empat projek, iaitu Turf Hoki, Mesin Basuh, My Dream Design dan Eco Friendly. Sumber data dalam kajian ini diperolehi daripada pemerhatian dan temubual. Pemerhatian dalam kajian ini dijalankan setiap hari iaitu dari hari Isnin hingga Jumaat selama 3 hingga 4 bulan untuk setiap kes. Semasa pembelajaran berlangsung pengkaji berada di dalam kelas bersama dengan guru dan kanak-kanak. Selain itu satu set soalan temu bual guru juga telah digunakan bagi mendapatkan data yang tidak dapat diperhatikan semasa pemerhatian. Sehingga temubual separa berstruktur telah dijalankan ke atas dua orang guru tadika. Jadual 1 adalah penjelasan mengenai profil guru yang akan dilibatkan dalam menjalankan kajian ini. Sedangkan untuk profil kanak-kanak yang terlibat juga turut dijelaskan dalam Jadual 2.

Jadual 1 Pengalaman serta Bidang Keahlian Peserta Kajian (Guru)

\begin{tabular}{lr}
\hline Peserta Kajian & Kriteria Pemilihan \\
\hline Guru Sri (PB) & $\begin{array}{r}\text { Guru berijazah Sarjana Muda dan Sarjana Pendidikan Awal Kanak- } \\
\text { kanak di UPSI. Pengalaman mengajar selama } 8 \text { tahun. }\end{array}$ \\
Guru Husna (PC) & $\begin{array}{r}\text { Guru berijazah Sarjana Muda dan Sarjana Pendidikan Awal Kanak-kanak } \\
\text { lepasan UPSI. Pengalaman mengajar selama } 7 \text { tahun. }\end{array}$ \\
\hline
\end{tabular}

Jadual 2 Peserta Kajian (Kanak-kanak)

\begin{tabular}{llcccc}
\hline Kelas & Projek & Umur & Jumlah & Lelaki & Perempuan \\
\hline Carnation (PE) & $\begin{array}{l}\text { Mesin Basuh } \\
\text { Turf Hoki }\end{array}$ & $4+$ & 20 & 11 & 9 \\
Aster (PF) & $\begin{array}{l}\text { My Dream Design } \\
\text { Eco Friendly }\end{array}$ & $5+$ & 16 & 8 & 8 \\
\hline \multicolumn{2}{c}{ Jumlah Keseluruhan } & 36 & 19 & 17 \\
\hline
\end{tabular}

Hasil dapatan kajian ini dianalisis apabila proses dalam mengumpulkan data telah selesai dijalankan. Data yang telah terkumpul di susun melalui proses analitikal sehingga menjadi lebih bermakna. Kaedah yang digunakan dalam penganalisisan kajian ini ialah analisis kandungan yang berdasarkan kepada tema sesuai pendapat (Miles, Huberman \& Saldana, 2014) serta juga dilakukan analisis secara naratif. Data pemerhatian, dan temubual yang telah selesai dikumpulkan dianalisis sesuai dengan pendekatan daripada Miles, Huberman dan Saldana (2014) dengan tiga hal utama, iaitu (1) melakukan reduksi data, (2) pemaparan data kajian dan (3) menghasilkan kesimpulan serta verifikasi (Rajah 1). 


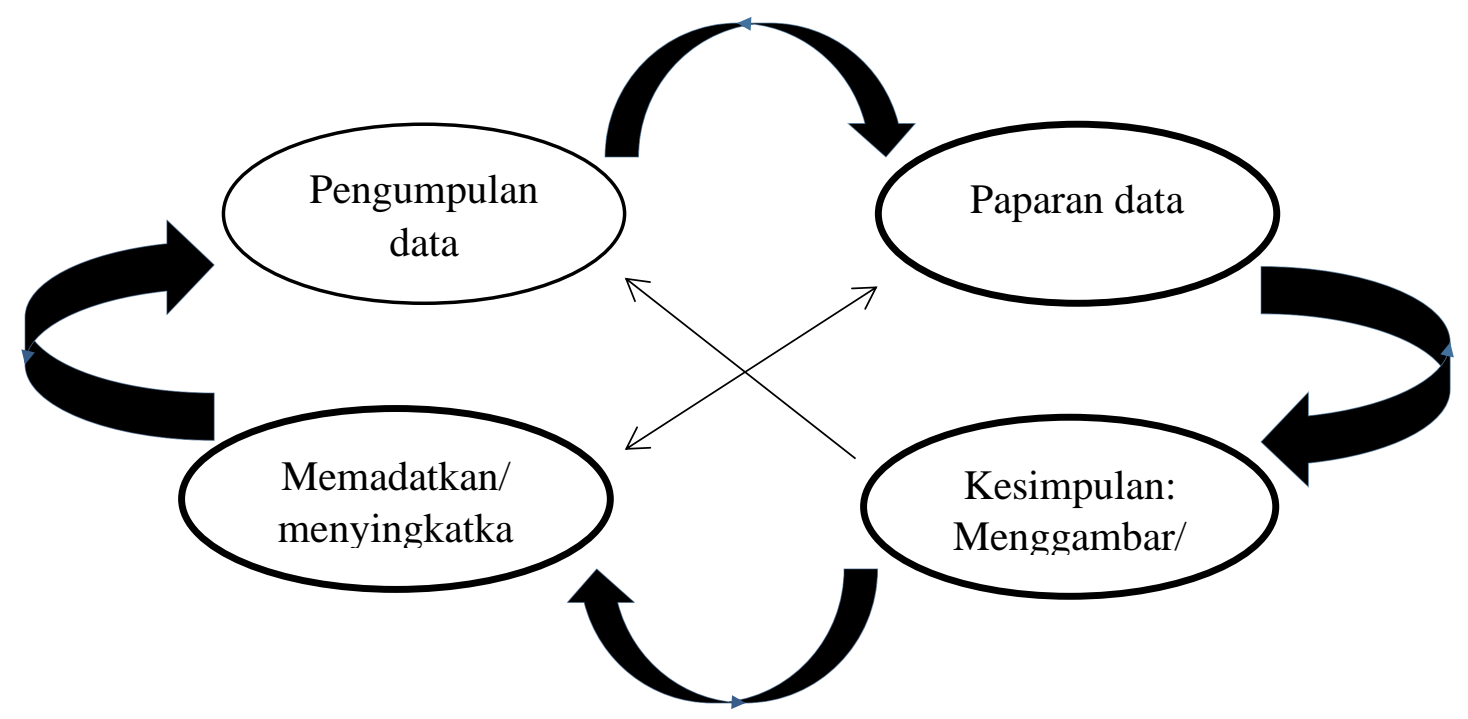

Rajah 1. Analisis data secara interaktif. Sumber daripada "Interactive Model” oleh Miles, Huberman \& Saldana, 2014, m.s.12.

\section{DAPATAN KAJIAN}

Hasil dapatan kajian ini untuk menjawab soalan "Apakah cabaran yang dihadapi oleh guru dalam menerapkan pendidikan STEM ke atas kanak-kanak prasekolah?" Dari hasil kajian ini telah didapati ada tiga cabaran utama guru dalam menjalankan pendidikan STEM. Pertama ialah pengetahuan guru, kanak-kanak dan juga ibu bapa, (2) penyediaan material untuk menjalankan aktiviti penyiasatan dan keterbatasan kewangan serta (3) halangan semasa menjalankan proses pengajaran dan pembelajaran terutama kurangnya tumpuan dan mood kanak-kanak.

\section{Pengetahuan Guru, Kanak-kanak dan Ibu Bapa}

Hasil kajian menunjukkan bahawa keterbatasan pengetahuan guru, kanak-kanak dan juga ibu bapa dapat mempengaruhi pengajaran STEM yang dijalankan di sekolah. Kefahaman kanak-kanak yang terhad dapat menghalangi mereka dalam menyerap ilmu pengetahuan yang telah disampaikan. Sebagaimana dapatan kajian yang diperolehi daripada guru Sri mengatakan bahawa:

"Pada saya kesediaan guru dan level pengetahuan guru itu adalah penting, kerana guru perlu dan mesti mempunyai pengetahuan yang lebih tentang aktiviti-aktiviti yang ingin dijalankan contohnya. Dan satu lagi halangan pada saya sepanjang menjalankan aktiviti STEM ini ialah level pengetahuan kanak-kanak. Kita tidak boleh menjangkakan semua kanakkanak mempunyai tahap atau level pengetahuan yang sama, sebaliknya terdapat kanak-kanak yang memang didedahkan dengan aktiviti-aktiviti atau program-program yang memerlukan kanak-kanak itu berfikir, diasah dengan soalan-soalan yang memerlukan kanak-kanak berfikir. Dan ada juga kanak-kanak yang hanya duduk, bermain gadget, menonton television. Dan mungkin kanak-kanak dalam kumpulan itu mempunyai level pengetahuan yang sangat rendah berbanding kanak-kanak yang memang didedahkan dengan aktiviti-aktiviti yang berfikir aras tinggi dan aktiviti-aktiviti yang memerlukan mereka berfikir. Seterusnya pengetahuan ibu bapa juga merupakan halangan sedikitlah, sedikit halangan kepada saya kerana bukan semua ibu bapa mempunyai pengetahuan yang sama seperti guru dan pengetahuan apa yang kanak-kanak perlu tahu. Saya selalu berikan task untuk ibu bapa, bukanlah saya tidak boleh memberi jawapan kepada kanak-kanak, tetapi saya memerlukan kerjasama ibu bapa, bagaimana maklumat daripada ibu bapa disalurkan kepada kanakkanak, dan kanak-kanak akan menyalurkan kembali maklumat kepada rakan-rakan dalam kelas. Dan ada juga ibu bapa yang hanya menggunakan Google, teknologi semata-mata untuk 
menyampaikan maklumat tanpa menggunakan pengetahuan yang solid daripada pengetahuan ibu bapa sendiri disalurkan kepada kanak-kanak, sebaliknya ibu bapa menggunakan video dan kanak-kanak datang bercerita apa yang dilihat bersama ibu bapa. Itu sahaja."

Pernyataan daripada guru Sri juga telah disokong oleh hasil temu bual dengan guru Husna yang menyatakan:

"Halangan yang dihadapi ini yang pertamanya dari segi terbatasnya ilmulah. Sebab kalau macam kita tahukan sebagai cikgu early childhood kita tak semua major dalam ni kan, so kita kena cari ilmu tu. Kadang-kadang terbatas jugalah. Contohnya kalau ada penyiasatan yang melibatkan ilmu fizik sikitkan, so kita macam kena buat research lebih. Bila kita nak sampaikan atau jalankan dengan anak-anak tu kita kena tengok yang betul, bukan kita boleh main bagi je dekat budak-budakkan. So, cikgupun kena buat research, cari buku yang daripada pakar-pakar tertentu, bukan je main ambe je daripada internet atau daripada mana sumber."

Dari hasil temu bual di atas dengan kedua orang guru dapat difahami bahawa pengetahuan yang terbatas sangat mempengaruhi proses pembelajaran menerusi STEM. Sehingga dapat disimpulkan bahawa cabaran yang dihadapi oleh guru ialah keterbatasan pengetahuan daripada guru sendiri, kanak-kanak serta ibu bapa telah menjadikan pembelajaran STEM kurang dilaksanakan dengan baik.

\title{
Penyediaan Material untuk Menjalankan Aktiviti
}

Cabaran seterusnya yang dihadapi oleh guru adalah peralatan atau material yang kurang mencukupi dalam menjalankan sesuatu penyiasatan juga telah dikesan sebagai satu punca cabaran guru dalam menjalankan pendidikan STEM. Aktiviti penyiasatan hands-on yang dijalankan oleh guru bersama kanak-kanak di dalam ataupun di luar bilik darjah yang memerlukan penyelesaian secara individu memerlukan peralatan atau material yang banyak. Sebagaimana pernyataan guru Sri berikut ini:

\begin{abstract}
"Selain pengetahuan guru penyediaan bahan dan material pelaksanaan aktiviti juga sangat penting. Cuba bayangkan semua aktiviti elemen STEM perlu melibatkan aktiviti hands-on. Apabila melibatkan aktiviti hands-on, persediaan bahan radas perlu lebih untuk kanak-kanak melakukan aktiviti secara individu walaupun ada aktiviti yang boleh dilakukan secara kumpulan kecil dan kumpulan besar tapi ada juga aktiviti-aktiviti yang memang kanak-kanak itu perlu melakukannya secara individu."
\end{abstract}

Sementara pendapat daripada guru Husna adalah segi kurangnya kewangan juga dapat menghalangi sebarang aktiviti kanak-kanak apalagi semasa aktiviti yang memerlukan banyak material ataupun peralatan. Walaubagaimanapun, cabaran ini kadangkala dapat diselesaikan apabila ibu bapa dapat menyokong dalam menyediakan peralatan tersebut. Sebagaimana hasil temu bual dengan guru Husna menyatakan bahawa:

"Lepas tu satu lagi halangan yang dihadapi kewangan jugalah, kadang-kadang bila kita buat
pembelajaran ni kita nak guna banyak bahan, banyak bendakan. Maksudnya kita nak kena
buat penyiasatan, tapi kalau kita pandai deal dengan parents oke jekan, kita minta tolong
kerjasama parentskan. So, parents akan bagi macam dia orang sponsor, nak beli bahan apa
ee dia orang bagie e macam tulah."

Hasil temu bual bersama kedua orang guru dapat disimpulkan bahawa peralatan atau material yang diperlukan untuk menjalankan pelbagai aktiviti pembelajaran menerusi STEM perlu mencukupi agar aktiviti-aktiviti yang dijalankan oleh guru bersama kanak-kanak dapat berlangsung dengan baik dan maksimal. Dengan demikian, cabaran daripada kekurangan peralatan dan kewangan dapat diatasi dengan baik. 


\title{
Proses Pengajaran dan Pembelajaran
}

Cabaran selanjutnya yang dihadapi oleh guru dalam menjalankan pendidikan STEM ialah kanakkanak kurang tumpuan semasa pembelajaran berlangsung. Hal ini menyebabkan penyampaian pengetahuan oleh guru kurang diterima oleh minda kanak-kanak. Sebagaimana pendapat yang dinyatakan oleh guru Husna ialah:

\begin{abstract}
"Halangan itu tidaklah kritikal sangat, tetapi biasanya kanak-kanak dalam Early Childhood ini dia kurang fokus. Itu salah satu halangannya. Bila dia kurang fokus, maka dia tak boleh tertumpu pada suatu aktiviti atau projek yang terlalu lama. Jadi, bila kanak-kanak bertumpuan berhad maka aktiviti kita juga terhad. Jadi benda tu akan jadikan mood kanakkanak itu juga terhad. Jadi halangan utamanya bagaimana kita nak kontrol kanak-kanak, itu yang pertama. Yang kedua, kita perlukan respon daripada kanak-kanak itu secara menjurus, jadinya kita tak boleh nak buat ramai-ramai kita kena pecahkan grup. Bila pecahkan grup kita kekangan daripada pembantu pengawasan murid. Jadi bila kita handle kelas, kita perlu juga pencatat. Bila kita nak cuba cari idea daripada kanak-kanak, kita perlukan juga orang yang ambil gambar. Jadi sekarang halangan yang pertama ketekalan ataupun tahap tumpuan kanak-kanak yang singkat terutamanya. Yang kedua kita tak cukup assistant, yang ketiga kita tak adapun pencatat yang boleh tolong kita semasa cikgu nak cuba tarik perhatian kanakkanak, sedangkan pembantu kita nak handle kanak-kanak, sebab kanak-kanak ni dia tak boleh duduk lama dan yang keempat kita perlukan orang lain yang bantu kita untuk dokumentasi ataupun untuk record setiap kali perbualan kita, setiap kali kita dengan budak-budak ada orang yang boleh tangkap gambar. Kita memang terhad itu je kekangan dia sekarang ee yang lain tu tak da masalahlah."
\end{abstract}

Seterusnya, guru Sri juga turut memberikan pendapatnya mengenai cabaran ini dan beliau menyatakan bahawa:

"Lepas tu lagi halangan yang dihadapi masa menjalankan elemen STEM ini, mood kanakkanak ada juga sebab kita tak boleh nak duga. Contoh bila mood kanak-kanak tak oke, setengah jam pun tak lepas nak pigi mana, macam tulah. So, mood kanak-kanak itu salah satu halangan jugalah.”

Selain itu, bagi guru persepsi ibu bapa juga dapat menjadikan satu cabaran bagi guru apabila menjalankan pelbagai aktiviti bersama kanak-kanak terutama aktiviti yang dijalankan di luar bilik darjah. Kadagkala ibu bapa kurang memberikan sokonga moral kepada guru semasa pembelajaran dijalankan. Sebagaimana hasil temu bual bersama guru Husna berikut ini:

\begin{abstract}
"Seterusnya, halangannya macam persepsi parents ataupun orang punya mindset. Tak semua parents tapi kebanyakan parentslah. Contohnya kalau macam kita ada aktiviti yang macam sebelum ni bagi pasal hujan. Parents macam jangan cikgu nanti anak saya demam apa semua. Sebenarnya itu mitos. Sebab saya ada baca dan saya ada tanya jugalah macam Dokterlah. Sebenarnya main hujan itu bukanlah yang menyebabkan demam, tapi dari segi antibody kita, metabolism penerimaan badan kita sebenarnya. Sebab kanak-kanak ni dia akan keluar idea dan soalan bila dia melalui benda tu."
\end{abstract}

\section{PERBINCANGAN}

Daripada hasil kajian yang telah dijalankan didapati bahawa cabaran guru ialah kurangnya pengetahuan guru mengenai pendidikan STEM. Wahono dan Chang (2017) dalam kajian mereka ke atas 137 orang guru sains mendapati bahawa cabaran guru dalam menjalankan pendidikan STEM ialah terbatasnya pengetahuan mereka dalam bidang STEM sehingga mereka memerlukan peningkatan pengetahuan dalam bidang pendidikan STEM. Usaha yang dapat dilakukan untuk memberikan sokongan kepada guru dalam menjalankan pendidikan STEM ialah dengan memberikan pengembangan profesional kepada guru terutama dalam bidang STEM (Margot \& Kettler, 2019). 
Sehingga pengetahuan mereka dapat bertambah dan menjadi lebih yakin dalam menngajarkan pendidikan STEM.

Seterusnya, tahap pengetahuan kanak-kanak juga menjadi satu cabaran bagi guru dalam hal ini. Pengetahuan kanak-kanak berbeza-beza antara satu dengan lainnya berdasarkan kepada pengalaman dan pendedahan pengetahuan masaing-masing mereka di lingkungan persekitarannya. Ada pelbagai faktor yang mempengaruhi pengetahuan kanak-kanak sebagaimana pendapat daripada Bagiati (2011) bahawa diantara faktor luar yang dapat mempengaruhi proses pembelajaran seseorang ialah berpunca daripada keluarga, kanak-kanak sendiri, bilik darjah dan batasan sosial.

Selanjutnya, cabaran dari segi penyediaan peralatan atau material untuk menjalankan penyiasatan juga telah dihadapi oleh guru semasa sesi pembelajaran berlangsung. Dapatan pemerhatian dan temu bual dengan guru menunjukkan bahawa guru mengalami kekurangan peralatan dan material semasa penyiasatan dijalankan apalagi semasa menjalankan aktiviti hands-on yang memerlukan alat radas yang bersesuaian dengan jumlah kanak-kanak. Sebagaimana hasil kajian yang telah dijalankan oleh Donelley (2018) mendapati bahawa diantara cabaran yang dihadapi oleh guru ialah mereka kurang pendedahan dari aspek latihan, peningkatan pendidikan dan pengalaman dalam bidang STEM. Mereka juga memiliki sumber dan bahan yang kurang serta masa yang terhad dalam menyokong penerapan pendidikan STEM.

Selain itu, dapatan kajian juga menunjukkan bahawa guru juga menghadapi cabaran semasa pengajaran dan pembelajaran dijalankan iaitu kanak-kanak memiliki minat dan tumpuan yang kurang baik. Kanak-kanak memang memiliki perbezaan minat dan tahap tumpuan yang berbeza-beza. Sebahagian mereka memiliki minat yang tinggi pada topik atau aktiviti pertama namun kurang berminat pada sesi yang lainnya. Inilah yang dimaksud dengan divergent interest. Helm dan Katz (2001) menyebutkan bahawa dalam setiap kumpulan kanak-kanak menujukkan tahapan minat yang sangat pelbagai sehingga sebahagian kanak-kanak menunjukkan respon yang baik dan mengambil bahagian dalam sesuatu aktiviti namun ada juga sebahagian yang lainnya menunjukkan minat yang rendah dalam menjalankan aktiviti tersebut.

\section{Implikasi Kajian}

Berdasarkan kepada dapatan kajian ini, pengkaji menawarkan beberapa pertimbangan kepada pihak yang berkepentingan dalam bidang pendidikan untuk memajukan pendidikan terutama dalam bidang STEM pada peringkat prasekolah.

\section{Sokongan daripada Kerajaan atau Pentadbir}

Dicadangkan pentadbir atau kerajaan untuk memberikan sokongan kepada guru prasekolah dalam menjalankan pengembangan profesional guru terutama dalam pendidikan STEM dimulai daripada peringkat daerah (penguasa, penyelaras kurikulum STEM dan pengarah dalam bidang pendidikan). Seterusnya, untuk meringankan cabaran guru dalam penyediaan peralatan atau material pembelajaran pula, diharapkan agar dapat menawarkan keperluan-keperluan yang mendasar dalam menjalankan aktiviti-aktiviti penyiasatan seperti penambahan sumber pembelajaran dan penjadualan yang fleksibel agar guru dapat merancang pembelajaran yang maksimal.

\section{Sokongan untuk Kanak-kanak}

Ada dua hal yang perlu diambil kira oleh guru dalam menyokong pembelajaran kanak-kanak dalam bidang STEM. Pertama, guru perlu berhati-hati dalam mempertimbangkan aktiviti pembelajaran dan guru perlu mahir dalam merancang aktiviti dari aspek kandungan dan juga proses pembelajaran yang boleh meningkatkan kefahaman pengetahuan kanak-kanak dalam bidang STEM. Kedua, cabaran dalam aspek minat atau motivasi kanak-kanak dalam pelbagai bidang menjadikan matlamat pendidikan STEM tidak dapat dicapai. Sehingga perlu dipertimbangkan pelbagai aktiviti yang menarik dalam pembelajaran sebagaimana yang telah diketahui bahawa kanak-kanak belajar pengetahuan yang baharu melalui cara-cara yang baharu pula (Ochterski \& Lupacchino-Gilson, 2016). 


\section{KESIMPULAN}

Ada pelbagai rintangan yang dihadapi oleh guru-guru yang mengajar di prasekolah terutama dalam mata pelajaran sains awal termasuk juga bidang STEM. Dapatan-dapatan dalam kajian ini juga telah banyak dijumpai dalam kajian lainnya, sehingga banyak maklumat yang dapat dipertimbangkan dalam menyelesaikan permasalahan yang dihadapi guru semasa menjalankan pendidikan STEM yang lebih berkesan terutama diperingkat prasekolah. Guru perlu berusaha dengan yakin dalam mencari solusi untuk mengatasi segala permasalahan yang dihadapi terutama dalam bidang STEM bagi mencapai kanak-kanak yang memiliki masa depan gemilang dan mampu bersaing dalam dunia kerja secara global. Guru juga perlu meningkatkan pengetahuan, keyakinan dan kepercayaan diri agar pengajaran menerusi STEM menjadi lebih efektif dan berkesan sehingga dapat meningkatkan pembelajaran kanak-kanak (Nadelson et al. 2012).

Dapatan kajian ini dapat dipergunakan sebagai panduan bagi tadika lainnya terutama pihak guru dalam menjalankan pendidikan STEM. Seterusnya, harapan untuk semua pihak yang memiliki peranan dalam meningkatkan kualiti pendidikan terutama peringkat prasekolah agar dapat berusaha memahami cabaran-cabaran guru secara mendalam sehingga dapat memberikan perhatian dengan langkah membantu guru dalam meningkatkan kemampuan mengajar terutama dalam bidang STEM.

\section{RUJUKAN}

Aini Aziziah Ramli, Nor Hasniza Ibrahim, Johari Bin Surif, Muhammad Abd Hadi Bunyamin, Rahimah Jamaluddin \& Nurdiana Abdullah. (2017). Teachers' readiness in teaching stem education. Man in India, 97 (13). pp. 343-350. ISSN 0025-1569.

Aminah Ayob, Mohd Nasir Ibrahim, Ong Eng Tek, Mazlina Adnan., Noriah Ishak., \& Jameyah Sheriff. (2015). Laporan kajian STEM untuk permata negara. Bahagian permata, Jabatan Perdana Menteri Malaysia.

Bagiati, A. (2011). Early Engineering: A Developmentally Appropriate Curriculum for Young Children. Doctoral Dissertation, School of Engineering Education, Purdue University.

Bers, M.U. (2008). Blocks, robots and computers: Learning about technology in early childhood.I New York: Teacher's College Press.

Brown, R., Brown, J., Reardon, K., \& Merrill, C. (2011). Understanding STEM: Current perceptions.Technology and Engineering Teacher, 70(1), 5-9. Retrieved from http://www.iteaconnect.org/ Publications/ TTTarticleindex13.htm.

Creswell, J. W., Hanson, W. E., Clark Plano, V. L., \& Morales, A. (2007). Qualitative research designs: Selection and implementation. The counseling psychologist, 35(2), 236-264.

Cunha, F. \& Heckman, J. (2007). The technology of skill formation. American Economic Review, 97(2), 3147.4

Denzin, K. N., \& Lincoln, S. Y. (2000). Handbook of Qualitative Research (2 ${ }^{\text {nd }}$ ed.). London: SAGE.

Donnelley Smith, A. R. (2018). Self-Efficacy of Early Childhood Teachers in Science, Technology, Engineering, and Mathematics.

Hanushek, E. A., Kain, J. F., \& Rivkin, S. G. (2004). Why public schools lose teachers. Journal of Human Resources, 39(2), 326-354

Hanushek, E. A., \& Rivkin, S. G. (2007). Pay, working conditions, and teacher quality. The future of children, 69-86.

Helm, J. H., \& Katz. L. G. (2001). Young Investigators: The project approach in the early years. New York, NY: Teachers College Press.

Jones, M. G., Jones, B. D., \& Hargrove, T. Y. (2003). The unintended consequences of high-stakes testing. Lanham, MD: Rowman \& Littlefield

Kelley, T. R., \& Knowles, J. G. (2016). A conceptual framework for integrated STEM education. International Journal of STEM Education, 3(1), 11.

Kementerian Pendidikan Malaysia (2015). Annual Report 2015 MALAYSIA EDUCATION BLUEPRINT 2013-2025. Malaysia.

Li, Y. (2014). International journal of STEM education-A platform to promote STEM education and research worldwide. International Journal of STEM Education 2014 1:1

Margot, K. C., \& Kettler, T. (2019). Teachers' perception of STEM integration and education: A systematic literature review. International Journal of STEM Education, 6(1), 2. 
McConnell, J. R. (2017). A model for understanding teachers' intentions to remain in STEM education. International Journal of STEM Education,4(1), 7. Diperolehi daripada https://www.springeropen.com/track/pdf/10.1186/s40594-017-00618 ? site $=$ stemeducationjournal.springeropen.com

McClure, E., Guernsey, L., Clements, D., Bales, S., Nichols, J., Kendall-Taylor, N., et al. (2017). STEM starts early: Grounding science, technology, engineering, and math education in early childhood. New York: The Joan Ganz Cooney Center at Sesame Workshop.

Merriam, S. B. (1998). Case Study Research in Education: A Qualitative Approach. CA: Jossey-Bass Inco.

Miles, M. B., Huberman, A. M. \& Saldana, J. (2014). Qualitative data analysis: A methods sourcebook. (3 ${ }^{\text {rd }}$ ed.). Thousand Oaks, CA: Sage Publication, Inc.

Moore, T. J., Johnson, C. C., Peter-Burton, E. E., \& Guzey, S. S. (2016). The need for a STEM road map. In C. C. Johnson, E. E. Peter-Burton, \& T. J. Moore (Eds.), STEM road map: Aframework for integrated STEM education (pp. 3-12). NY: Routledge Taylor \& Francis Group.

Nadelson, L. S., Seifert, A., Moll, A. J., \& Coats, B. (2012). i-stem summer institute: an integrated approach to teacher professional development in stem. Journal of STEM Education: Innovations and Research, 13(2), 69-83. Diperolehi daripada www.jstem.org

Ochterski, J., \& Lupacchino-Gilson, L. (2016). Getting an A in STEM: Beginning a steam collaboration between art and chemistry students. The Science Teacher, 83(7), 39. doi:10.2505/4/tst16_083_07_39

Othman Lebar. (2017). Penyelidikan Kualitatif: Pengenalan kepada teori dan metode. (Edisi kedua). Tanjong Malim: Universiti Pendidikan Sultan Idris.

Sanders, M. (2009) STEM, STEM education, STEMmania. The Technology Teacher, 68(4).20-26.

Sobey, N. (2019). Does Working in Collaborative Groups to Complete STEM Design Challenges Increase Student Engagement Among Preschool-aged Children? (Doctoral dissertation, Hofstra University).

Stohlmann, M., Moore, T. J. \& Roehrig, G. H. (2012). Considerations for teaching integrated STEM education. Journal of Pre-College Engineering Education Research, 2(1), Article 4. https://doi.org/10.5703/1288284314653

Tight, M. (2017). Understanding case study research: Small-scale research with meaning. ( $1^{\text {st }}$ edition). London, Sage.

Torres-Crespo, M. N., Kraatz, E., \& Pallansch, L. (2014). From Fearing STEM to Playing with It: The Natural Integration of STEM into the Preschool Classroom. SRATE Journal, 23(2), 8-16.

Wahono, B., \& Chang, C. Y. (2019). Assessing teacher's attitude, knowledge, and application (aka) on stem: an effort to foster the sustainable development of stem education. Sustainability, 11(4), 950.

Winarni, J., Zubaidah,. S., Koes, H. S., (2016). STEM: Apa, Mengapa, dan Bagaimana. Prosiding Seminar Pendidikan IPA Pascasarjana Universitas Negeri Malang. Vol. 1, 2016, ISBN: 978-602-9286-21-2.

Yin, R. K. (2015). Qualitative research from start to finish. (2 ${ }^{\text {nd }}$ ed.). New York, NY: The Guilford Prublications. 